\title{
Возникновение зеленой окраски в кристаллах AIN, выращенных на затравках SiC
}

\author{
() С.С. Нагалюк, Е.Н. Мохов, О.П. Казарова, Б.Я. Бер, А.А. Анисимов, И.Д. Бреев \\ Физико-технический институт им. А.Ф. Иофрфе Российской академии наук, \\ 194021 Санкт-Петербург, Россия \\ E-mail: snagalyuk@gmail.com
}

Поступила в Редакцию 19 фревраля 2021 г.

В окончательной редакции 25 февраля 2021 г.

Принята к публикации 25 февраля 2021 г.

Исследованы причины, приводящие к появлению зеленой окраски кристаллов AlN, выращиваемых методом сублимации на затравках $\mathrm{SiC}$. Методом вторичной ионной масс-спектроскопии показано, что цвет кристаллов слабо зависит от содержания кремния и углерода, а зеленая или темная окраска возникает только при повышенном содержании углерода по сравнению с кремнием. Методом комбинационного рассеяния света установлено присутствие в этих кристаллах отдельной фазы аморфного углерода. Выделение фазы углерода в процессе роста кристаллов затрудняет получение качественных кристаллов AlN, а также твердых растворов $\mathrm{AlN}-\mathrm{SiC}$. Анализируется влияние условий роста на оптические свойства кристаллов AlN.

Ключевые слова: кристалл $\mathrm{AlN}$, затравка $\mathrm{SiC}$, зеленая или темная окраска, аморфный углерод.

DOI: 10.21883/FTP.2021.06.50919.9635

\section{1. Введение}

Нитрид алюминия (AlN) относится к широкозонным полупроводникам с большой энергией связи, на базе которого могут быть созданы различные оптоэлектронные приборы, в том числе ультрафиолетовые светоизлучающие диоды, лазерные диоды, а также мощные высокочастотные электронные приборы и пьезоэлектрические резонаторы [1]. Однако для успешной реализации промышленного производства таких приборов требуются высококачественные объемные кристаллы AlN большого диаметра (4 дюйма и более), используемые в качестве подложек.

Такие кристаллы могут быть получены путем гомоэпитаксиального роста слитков на затравках AlN. Но кристаллы требуемых размеров пока еще труднодоступны, а использование более мелких кристаллов с последующим их разращиванием оказывается весьма сложным и недостаточно воспроизводимым процессом.

Поэтому при выращивании объемных кристаллов AlN часто используются инородные затравки, например $\mathrm{SiC}$, тем более что к настоящему времени освоено производство слитков $\mathrm{SiC}$ с размерами до 200 мм. Однако проблемой при гетероэпитаксиальном росте является загрязнение растущего кристалла примесями, попадающими из материала затравки. Например, при росте AIN на положках $\mathrm{SiC}$ уровень содержания $\mathrm{Si}$ и $\mathrm{C}$ составляет порядка нескольких процентов.

Следует отметить, что большая ширина запрещенной зоны у AlN (6.2 эВ) должна позволять получение бесцветных кристаллов AlN. Однако, как правило, даже кристаллы с низким содержанием примесей имеют янтарную или светло-желтую окраску, которая обычно связывается с присутствием примеси кислорода [2].
Цвет кристаллов, выращенных на подложках $\mathrm{SiC}$, может различаться от желтого до темно-зеленого [3-7].

Причина появления зеленой окраски остается невыясненной [3-5]. Основными легирующими примесями в таких кристаллах являются кремний и углерод. Однако высокую концентрацию $\mathrm{Si}, \sim 10 \%$, могли иметь кристаллы как с желтой, так и с зеленой окраской [3]. Делалось также предположение о возможном влиянии на окраску углерода, но используемый для анализа углерода ЕРМАметод не обладает достаточной чувствительностью, чтобы делать определенные выводы о его влиянии на цвет $[3,6]$. К тому же при одинаковых условиях роста на on-axis (0001) грани росли синие кристаллы, в то время как на подложках с большим углом разориентации цвет кристалла оставался желтым [7].

В ряде работ отмечалось, что изменение окраски $\mathrm{AlN}$ от желтой к зеленой, как правило, сопровождается ухудшением качества кристаллов [3,5]. Но причина ухудшения оставалась не ясной.

Цель настоящей работы заключалась в выяснении причин, вызывающих изменение окраски выращиваемых кристаллов AlN на SiC-затравках. Для этого исследовалось влияние условий кристаллизации на оптические характеристики с использованием методов, позволяющих не только определить содержание примесей в кристаллах, имеющих различную окраску, но и проанализировать, в каком состоянии находятся примеси.

\section{2. Эксперимент}

Методика сублимационного роста кристаллов AlN, используемая в настоящей работе, подробно описана ранее [8]. Рост велся в танталовых тиглях, которые предварительно карбидизировались, в процессе высоко- 

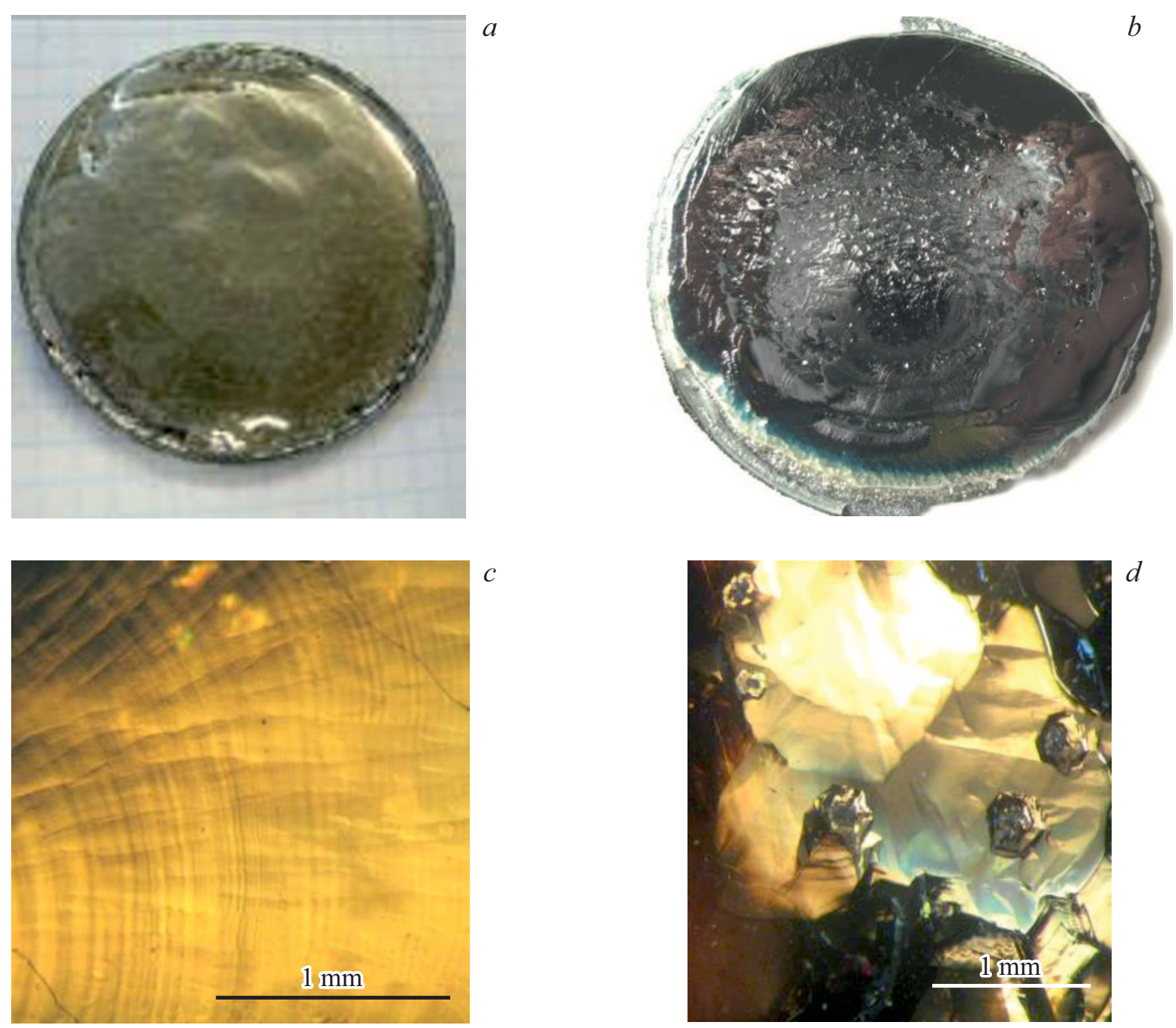

Рис. 1. Фотография светло-желтого $(a)$ и темно-зеленого $(b)$ образца $\mathrm{SiC}$, выращенного на затравке $6 H$ - $\mathrm{SiC}$, и морфология ростовой поверхности этих образцов $(c, d)$.

температурного отжига в среде графитового порошка. Приготовленные таким образом контейнеры обладали высокой герметичностью. Потери сублимирующего источника обычно не превышали $2 \%$. В качестве подложек использовались пластины $\mathrm{SiC}$, политипа 6H. Угол разориентации ростовой поверхности к базисной (0001) грани не превышал $1^{\circ}$. Источником паров $\mathrm{AlN}$ служил высокочистый порошок AlN, отожженный в атмосфере азота при $2100^{\circ} \mathrm{C}$, в который добавлялось определенное количество карбида кремния.

Выдерживались следующие основные параметры ростового процесса:

температура затравки $1900-2000^{\circ} \mathrm{C}$, величина зазора между источником и подложкой - 3-10 мм, градиент температуры в зоне роста $-\sim 5^{\circ} \mathrm{C} / \mathrm{MM}$,

давление азота в ростовой камере - 0.1-1 атм. Продолжительность процесса кристаллизации составляла 20-30 ч. Выращиваемые кристаллы имели диаметр 50 мм и более, толщину $-1-5$ мм.
Для исследования использовались методы рентгеновской дифрактометрии, комбинационного рассеяния и оптической микроскопии. Содержание примесей определялось методом вторичной ионной масс-спектрометрией (ВИМС).

\section{3. Результаты и их обсуждение}

Было проведено значительное число экспериментов по росту объемных кристаллов $\mathrm{AlN}$ на $\mathrm{SiC}-$ затравках. Большинство кристаллов, выращенных в оптимальных условиях, имело желтый цвет. Однако некоторые кристаллы имели зеленоватую или темно-синюю окраску (рис. 1, $a, b)$.

Видно, что поверхность желтых кристаллов имеет типичный слоевой рельеф, а поверхность темно-зеленых кристаллов оказывалась существенно более грубой.

Изменение цвета кристаллов от желтого к зеленому нередко наблюдалось в одном кристалле, особенно в 

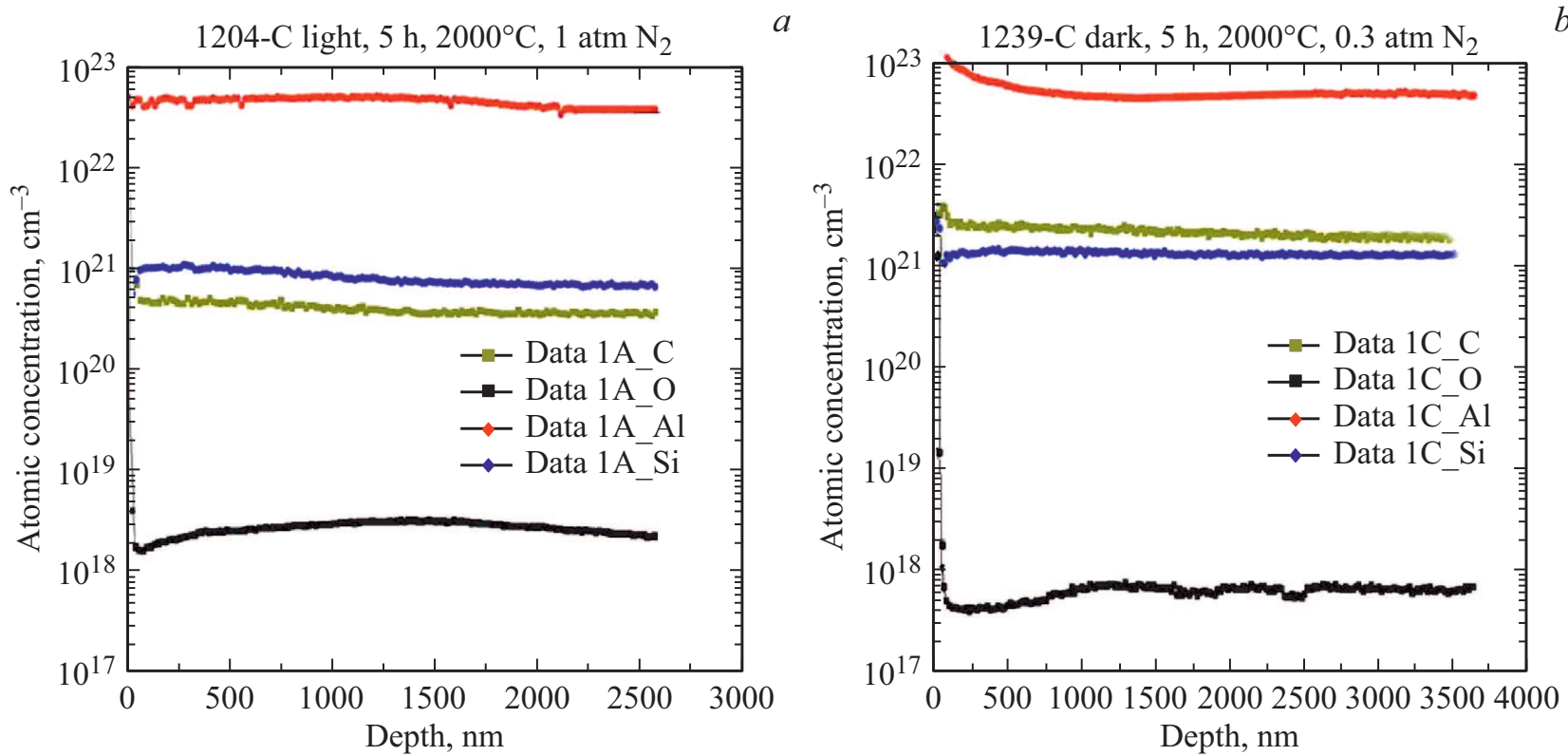

Рис. 2. Концентрация примесей в кристаллах $\mathrm{AlN}$ различной окраски, выращенных на затравке $\mathrm{SiC}$, политипа $6 H: a-$ желтый кристалл, $b$ - темный кристалл.
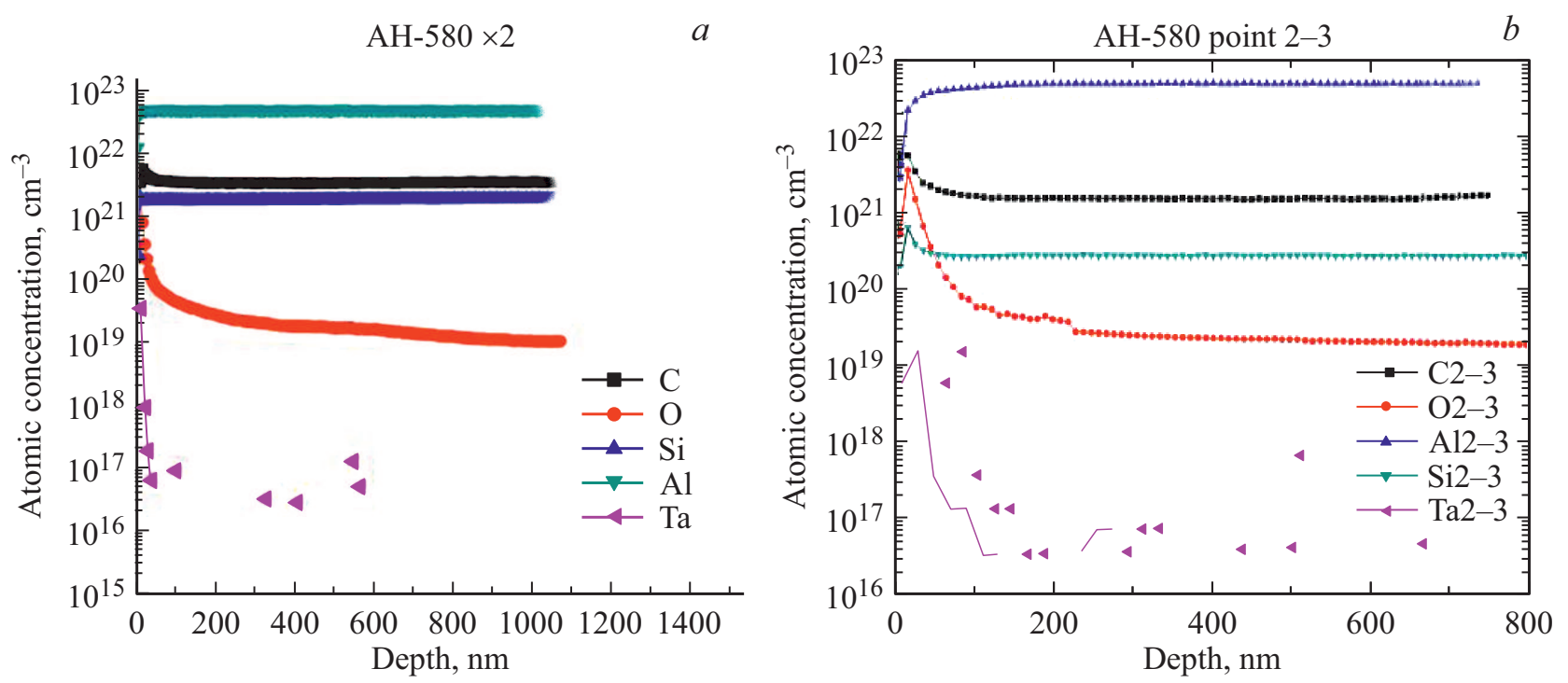

Рис. 3. Концентрация примесей в темном кристалле $\mathrm{AlN}$, выращенном на затравке $\mathrm{SiC}$, политипа $6 H$ : $a-$ вблизи интерфейса $\mathrm{SiC}-\mathrm{AlN}, b-$ на расстоянии 3.5 мм от затравки.

длительных процессах, продолжительностью более 30 ч. Ухудшение герметичности контейнера также приводило к появлению зеленоватой окраски кристаллов. Тщательный контроль массопереноса позволил установить, что желтые кристаллы растут при условии, что эвакуация сублимируемого источника AlN из контейнера не превышает 3-5\%.

При дальнейшем исследовании были вскрыты факторы, влияющие на цвет кристалла. Выяснилось, что повышенная температура роста (выше $2000^{\circ} \mathrm{C}$ ), а также пониженное давление азота (ниже 0.2 атм) способствуют появлению зеленой окраски. Изменение цвета растущих кристаллов от желтого к зеленому сопровождалось ухудшением структурного совершенства кристалла. Ростовая поверхность становится более грубой за счет образования новых $3 d$-центров (рис. $1, c, d)$.

На рис. 2. представлена концентрация основных примесей в желтом и зеленом кристаллах AIN, выращенных сублимацией при одинаковых условиях роста.

Как видно из рис. 2, цвет кристалла почти не зависит от содержания углерода и кремния. Кристаллы желтого цвета могут быть выращены как при низкой 


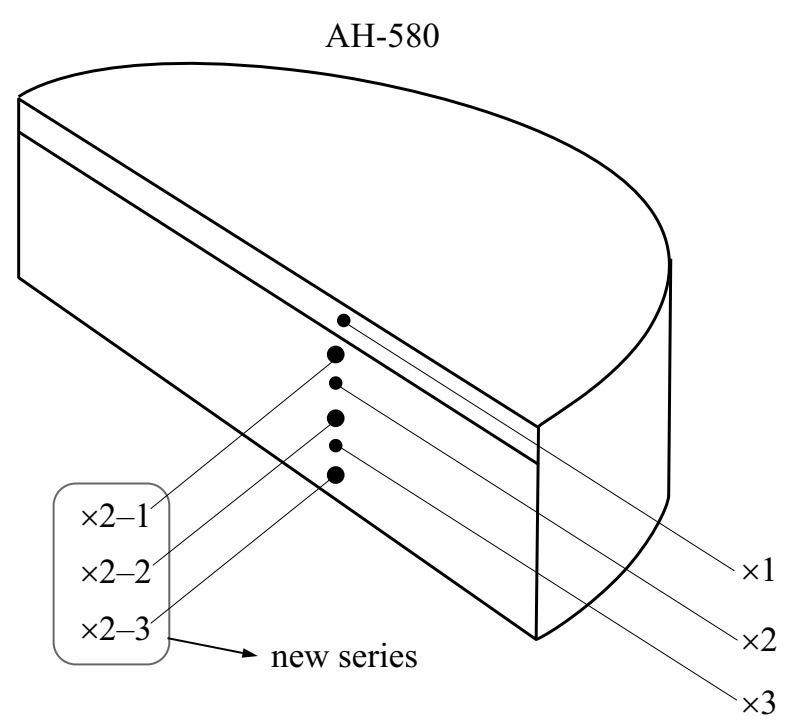

Рис. 4. Схематическое изображение поперечного скола слитка. Сверху затравочный кристалл $(\times 1)$.

концентрации примесей, так и при предельно высоком их содержании, $\sim 10-15 \%$, когда источник содержал значительное количество $\mathrm{SiC}$.

Не было выявлено влияния кислорода на зеленый цвет, повышенное содержание которого приводило к резкому ухудшению качества роста. Однако важно отметить, что в зеленых и темных кристаллах содержание углерода было выше, чем кремния, в то время как в желтых кристаллах наблюдалось обратное соотношение содержания этих примесей (рис. 2).

В работе также изучалось распределение концентрации примесей по длине слитка. Содержание примесей определялось в разных точках на сколе кристалла. Для этого концентрация примесей определялась на поперечных сколах или на косых шлифах в различных точках наращенного слоя (рис. 3). Видно, что в процессе роста концентрация кремния в AlN значительно снижается по сравнению с содержанием углерода, что, очевидно, обусловлено частичной эвакуацией паров кремния. На рис. 4 приведено схематическое изображение поперечного скола слитка.

С помощью метода комбинационного рассеяния света (КРС) был исследован образец $\mathrm{AlN} / \mathrm{SiC}$, для которого ранее были проведены исследования ВИМС для определения концентрации содержащихся атомов в разных точках на разном расстоянии от интерфейса $\mathrm{AlN} / \mathrm{SiC}$ (рис. 3). Цель исследований - определить кристаллическое качество образца, интерфейса, а также попытаться установить связь между характеристиками пиков КРС с данными ВИМС. Для исследований использовалась следующая конфигурация спектрометра КРС. Использовался полупроводниковый лазер 532 нм, 5 мВт. Образец исследовался с торца в геометрии обратного рассеяния в двух основных геометриях КРС Y(X;0)-Y и Y(Z;0)-Y.
Доступ к ростовой поверхности образца был ограничен блестящей поверхностью, которая предварительно напоминает металл $\mathrm{Al}$, т.е. получить спектры в геометрии $\mathrm{Z}(\mathrm{X} ; 0)-\mathrm{Z}$ не представлялось возможным. Из-за больших перепадов высот рельефа на исследуемом торце образца мы были вынуждены использовать объектив $100 \times, 0.75$ NA с меньшим телесным углом сбора света, из-за чего интенсивность получаемых спектров КРС была ограничена.

Для получения спектров КРС AlN использовали дифракционную решетку 2400 штрих/мм с длиной волны блеска 400 нм. Для анализа спектров КРС аморфного углерода и спектров $\mathrm{AlN}$ и $\mathrm{SiC}$ одновременно мы использовали решетку с 1800 штрих/мм с длиной волны блеска 500 нм.

Было проведено исследование интерфейса между $6 H$-SiC и AlN. Оказалось, что на поверхности скола находится большое количество конгломератов аморфного углерода. Был найден гладкий участок интерфейса, для которого было проведено поперечное сканирование с записью спектров КРС. Помимо больших конгломератов углерода около интерфейса, углерод присутствовал на всем протяжении скола на поверхности AlN. Пример спектра КРС аморфного углерода на сколе представлен на рис. 5.

Таким образом, цветовая окраска зеленых и темных кристаллов AlN возникает в кристаллах с повышенной концентрацией углерода. Изменение цвета от светложелтого к зеленому, синему или темному естественно объяснить захватом растущим кристаллом в виде включений аморфного углерода. Действительно, нами установлено, что добавление углерода в источник также ведет к изменению цвета растущего кристалла от желтого к зеленому.

Зеленая окраска кристаллов сохраняется при диффузионном введении в кристалл примеси бериллия, в отличии от желтых кристаллов, которые обесцвечиваются [9]. Эти результаты свидетельствуют в пользу того, что

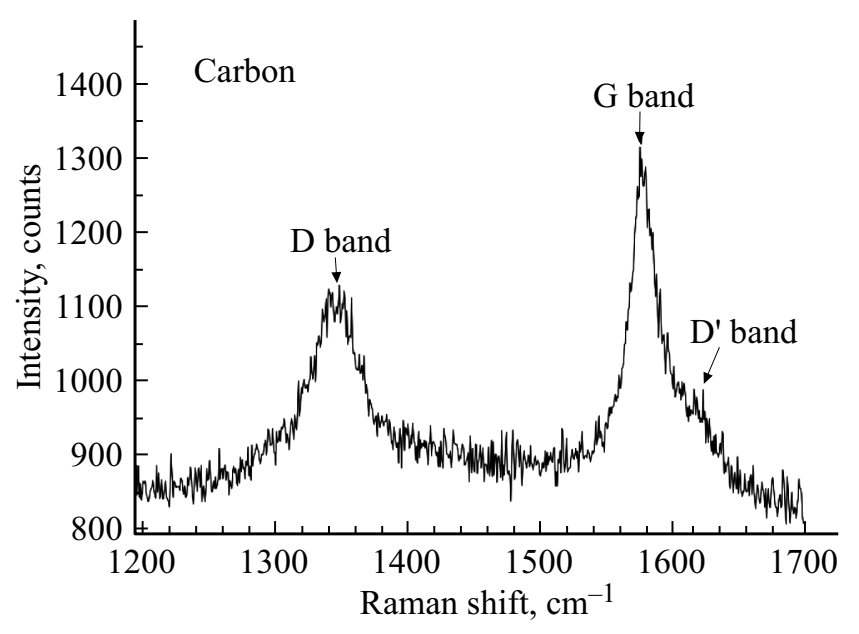

Рис. 5. Спектр КРС аморфного углерода на интерфейсе $\mathrm{AlN} / \mathrm{SiC}$. 
углерод находится не в атомарном состоянии, а образует включения отдельной фазы, влияющей на оптические свойства материала.

Присутствие кремния на поверхности растущего кристалла, очевидно, затрудняет выделение углерода в виде отдельной фазы. Поэтому добавление кремния (или карбида кремния) в источник AlN способствует росту качественных светлых кристаллов. Потемнение кристаллов AlN в процессе длительного роста, особенно при недостаточной герметичности контейнера, связано с испарением значительной части кремния. Очевидно, что повышение температуры приводит к тому же эффекту.

Отметим, что выделение свободного углерода (графитизация) является существенным препятствием для выращивания качественных кристаллов не только нитрида алюминия, но и карбида кремния [10].

\section{4. Заключение}

Методом комбинационного рассеяния света обнаружена фаза аморфного углерода, которая является одной из причин появления зеленой или более темной окраски в кристаллах AlN, выращенных на затравках $\mathrm{SiC}$. При повышенном содержании кремния по сравнению с углеродом вероятность образования углеродной фазы снижается и растут желтые кристаллы даже при высоком содержании примесей кремния углерода и кислорода. Частичная эвакуации паров кремния из контейнера за счет недостаточной его герметичности, повышенная температура кристаллизации или низкое давление паров азота приводят к росту зеленых или темных кристаллов. Выделение углерода на растущей поверхности затрудняет слоевой рост и, как следствие, ведет к ухудшению качества выращиваемого кристалла нитрида алюминия.

\section{Конфликт интересов}

Авторы заявляют, что у них нет конфликта интересов.

\section{Список литературы}

[1] Ziyi Zhang, Maki Kushimoto, Tadayoshi Sakai, Naoharu Sugiyama, Leo J. Schowalter, Chiaki Sasaoka, Hiroshi Amano. Appl. Phys. Express, 12, 124003 (2019). DOI: $10.7567 / 1882-0786 / \mathrm{ab} 50 \mathrm{e} 0$

[2] C. Guguschev, A. Dittmar, E. Moukhina, C. Hartmann, S. Golka, J. Wollweber, M. Bickermann, R. Fornari. J. Cryst. Growth, 360, 185 (2012).

[3] R.R. Sumathi, P. Gille. Cryst. Res. Technol., 47 (3), 237 (2012).

[4] M. Bickermann, O. Filip, B.M. Epelbaum, P. Heimann, M. Feneberg, B. Neuschl, K. Thonke, E. Wedler, A. Winnacker. J. Cryst. Growth, 339, 13 (2012).

[5] O. Filip, M. Bickermann, B.M. Epelbaum, P. Heimann, A. Winnacker. J. Cryst. Growth, 312, 2822 (2010).
[6] Seung-Min Kanga, Chel-Jong Choib, Jong-Won Yoon. J. Ceramic Proc. Res., 10 (5), 689 (2009).

[7] C.M. Balkas, Z. Sitar, T. Zheleva, L. Bergman, R. Nemanich, R.F. Davis. J. Cryst. Growth, 179, 363 (1997).

[8] O.V. Avdeev, T.Yu. Chemekova, H. Helava, M.G. Ramm, Yu.N. Makarov, E.N. Mokhov, S.S. Nagalyuk, A.S. Segal. In: Comprehensive Semiconductor Science and Technology (2011) p. 282.

[9] Е.Н. Мохов, М.К. Рабчинский, С.С. Нагалюк, М.Р. Гафуров, О.П. Казарова. ФТП, 54 (3), 224 (2020).

[10] B.M. Epelbaum, M. Bickermann, S. Nagata, P. Heimann, O. Filip, A. Winnacker. J. Cryst. Growth, 305 (2), 317 (2007).

Редактор Г.А. Оганесян

\section{Origin of green coloration in AIN crystals grown on SiC seeds}

\author{
S.S. Nagalyuk, E.N. Mokhov, O.P. Kazarova, B.Y. Ber, \\ A.A. Anisimov, I.D. Breev \\ loffe Institute, \\ 194021 St. Petersburg, Russia
}

\begin{abstract}
The origns leading to the appearance of a green color of AlN crystals grown by sublimation on $\mathrm{SiC}$ seeds are investigated. It was shown by the method of secondary ion mass spectroscopy that the color of crystals weakly depends on the content of silicon and carbon, and a green or dark color appears only with an increased content of carbon in comparison with silicon. The presence of a separate amorphous carbon phase in these crystals was established by the method of Raman light scattering. The separation of the carbon phase in the process of crystal growth makes it difficult to obtain high-quality AlN crystals, as well as AlN-SiC solid solutions. The influence of growth conditions on the optical properties of AlN crystals is analyzed.
\end{abstract}

